Recurrent depressive attacks can often be prevented ${ }^{9}$ by giving a small maintenance dose of an antidepressant drug and increasing it as soon as the symptoms recur. The drug may need to be continued for some months or even years after recovery, otherwise relapse will occur.

Of the different types of monoamine-oxidase inhibitors iproniazid $^{10}$ is still the most effective, especially when the depression is combined with severe tension. Despite its toxicity there are cases in which, all other treatment having failed, the risk of giving the drug seems justifiable. Isocarboxazide (Marplan), phenelzine, and phenoxypropazine (Drazine) are nearly comparable drugs and can be used as alternatives. Tranylcypromine (Parnate) is the only monoamine-oxidase inhibitor that is not a hydrazine. Its action seems to fall halfway between that of the hydrazine group and imipramine. It is a useful drug in general practice for the mildly depressed, "exhausted" patient with somatic symptoms-in fact the type of patient who responds temporarily to amphetamines.

There are several drugs similar to imipramine. Amitriptyline (Tryptyzol) probably has more sedative and less antidepressant effect, but reports ${ }^{11} 12$ so far are conflicting. Opipramol (Insidon) has a structural resemblance to imipramine and perphenazine but has not yet been properly tested. It is known to have a strong sedative effect, as does nortriptyline, which has also not yet been adequately assessed.

\section{Bone-marrow Grafts}

Bone-marrow " grafts" consist of marrow cells obtained by aspiration, usually from the iliac bones. The aspirated marrow is suspended in a saline solution, treated to clear most fat and possible fragments of bone or connective tissue, and stored for a short time at $4^{\circ} \mathrm{C}$. or for a long time at $-79^{\circ} \mathrm{C}$. in glycerol. The marrow aspirate is given intravenously to the recipient. The cells find their way to the marrow and are mostly retained there.

There are several possible sources of marrow-graft material. Autologous grafts come from the patient himself or the animal used in an experiment. Autologous marrow is mostly used in short-term treatment: for instance, a large dose of a rapidly acting cytostatic drug may be given for the treatment of malignant disease and marrow withdrawn to be put back into the patient some hours later. Isologous grafts are from individuals of identical genetic constitution. In man this means an identical twin; in animals it means that a highly inbred strain of constant constitution is used. Homologous grafts are from another individual of the same species-that is, from another man. Precautions are usually taken to ensure that the recipient and donor have no avoidable differences-for example, the blood groups. are as nearly identical as possible.

Bone-marrow grafts were used in human disease after it had been found that infusion of spleen or marrow cells protected animals from the effects of large doses of radiation. The use of such grafts in man was considerably stimulated by their successful use by G. Mathé and his colleagues ${ }^{1}$ in the treatment of five Yugoslav scientists who were accidentally irradiated with $\gamma$-rays and neutrons. Although the grafts survived only for three weeks, this was sufficient to tide the patients over the aplastic phase until their own production of marrow revived. In man most grafts must be of homologous marrow. Autologous marrow is used only to cover the administration of large doses of a cytotoxic drug like nitrogen mustard: a quantity of marrow is withdrawn from such a patient who is to have treatment, usually for a malignant condition ; the marrow is stored at $4^{\circ} \mathrm{C}$. in saline ; the action of the intravenously administered nitrogen mustard is over in a few hours at most, so the autologous marrow is returned to the patient in the hope that it will provide him with a source of marrow cells which have not been exposed to the toxic effects of the drug. The results of using such grafts have been doubtful, and M. G. Dunnigan and Alexander Brown ${ }^{2}$ have lately stated that they do not help the marrow to recover or mitigate the effects of the severe pancytopenia caused by the nitrogen mustard.

When homologous marrow is used the graft will not be tolerated by the host-that is, the patient-for long unless the patient's immune reactions can be modified, and matching of blood groups only slightly reduces the reaction. The usual way of overcoming this intolerance has been to give the host a nearly lethal dose of radiation before administering the graft. More recently various cytotoxic drugs have been tried. The dose of whole-body irradiation has to be so large that for the time being the patient is an " immunological cripple" with a lymphoid system that is incapable of proper reactions. It is in this way that graft treatment has been attempted for leukaemia. In this condition there is the additional possibility that the radiation would destroy the leukaemic tissue and that the patient's marrow could be repopulated by healthy cells. In practice this method has proved dangerous and disappointing; many patients succumbed to overwhelming sepsis before the graft could take, and even if the patient survived these initial hazards there was evidence that the leukaemia returned after an interval of about three months. Another attempt to surmount this problem of intolerance was the use of foetal cells ; such cells are "immunologically immature" and the foetal marrow contains a high proportion of primitive cells; H. E. M. Kay and M. Constandoulakis ${ }^{3}$ described the use of a foetal tissue bank. But such tissues are necessarily limited, and in practice the homograft reaction was no more than delayed.

A new difficulty, and an even more serious one, arose when it was found that a severe, often fatal, reaction occurred after the administration of the graft at a time when the initial hazards had been overcome and the graft was successfully proliferating. This reaction produces the so-called " runt disease " in animals, described at length by $N$. W. Nisbet and B. F. Heslop. ${ }^{4}$ In man the reaction, usually called "secondary disease," causes progressive loss of weight, diarrhoea due to loss of intestinal epithelium, skin lesions with desquamation, failure of liver function, and hypoplasia of the lymphoid tissues. Many patients treated with homologous marrow have succumbed to this secondary disease. Drs. Mathé and Amiel in their article at page 527 of the B.M.J. this week record that two out of three patients with leukaemia treated by irradiation and grafting died of secondary disease after myeloid restoration had occurred and neutropenia and thrombocytopenia had been corrected; in some patients the

\footnotetext{
1 Mathé, G., Bernard, J., Schwarzenberg, L., Larrieu, M. J., Lalanne Cl. M., Dutreix, A., Denoix, P. F., Surmont, J., Schwarzmann, V. and Céoara, B., Rev. franc. Etud. clin. biol., 1959, 4, 675.

2 Dunnigan, M. G. and Brown, A., Lancet, 1963, $2,477$.

Kay, H. E. M., and Constandoulakis, M., Brit. med. $¥ ., 1959,1,575$.

- Nisbet, N. W. and Heslop, B. F, ibid., 1962, 2, 129 and 206.

- Mathé, G., Amiel, J. L., Schwarzenberg, L., Cattan, A., and Schneider, M., ibid., 1963, 2, 1633.

- Mills, S. D., Kyle, R. A., Hallenbeck, G. A., Pease, G. L. and Cree, I. C., f. Amer. med. Ass., 1964, 188, 1037.

7 Thomas, E. D., Phillips, J. H., and Finch, C. A., ibid., 1964, 188, 1041.
} 
secondary syndrome has been eventually controlled. The occurrence of the secondary syndrome is at present the main reason for the reluctance to use marrow grafting as a method of treatment.

Drs. Mathé and Amiel discuss these problems in their article and outline their method of matching recipient and donor, which they hope will reduce the immune reactions. They also describe the use of homologous marrow-graft material derived from several sources and given in a " $\mathrm{mix}$ ture," which they reported last year..$^{5}$ Their patient, who had leukaemia, was given whole-body radiation from a cobalt-60 bomb and then given an intravenous infusion of marrow from six donors-his father, mother, sister, and three brothers. The secondary reaction appeared in about ten days and lasted eight weeks before it was controlled. Eight months later the patient's blood was completely repopulated with red cells which showed the characteristics of one of the donors, and the leukaemia was in complete remission. The idea seems to be that the recipient should be given the possibility of choosing the best donor material out of several which are antigenically closely related.

Bone-marrow grafting has also been attempted for the treatment of aplastic anaemia, but has on the whole met with little success because it is especially dangerous to suppress the patient's immune reactions with radiation. Consequently the grafts rarely survive. However, when the patient has an identical twin the possibility of using isologous marrow exists. Two such cases have been recently reported from America. S. D. Mills and associates ${ }^{6}$ gave a graft from an identical twin to a 9-year-old girl who had had an aplastic anaemia of unknown origin for two years and had failed to respond to standard treatment with transfusion, steroids, anabolic drugs, and even splenectomy. No further transfusions were needed after the marrow graft, and the patient had remained well for five months. The other case was reported by $E$. D. Thomas and associates. ${ }^{7}$ This was also a 9-year-old girl with idiopathic aplastic anaemia who had been ill for seven months and had not responded to treatment with transfusions and steroids. She was given an infusion of marrow cells from her identical twin, and remains well without further treatment 18 months later. Such cases are rare, but underline the fact that, if the immunological problems can be overcome, marrow grafting can become a practical possibility. The methods of preparation and storage of marrow material are now well worked out and are not particularly difficult. But it is clear from the article of Mathé and Amiel that the problem is as yet far from solved.

\section{Prognosis in Rheumatoid Arthritis}

Our knowledge of the prognosis of rheumatoid arthritis has increased in recent years. This is partly because the study of it in general has led to a more precise delineation of the disease, and partly because prospective long-term investigations have clarified its natural history and helped us to evaluate the prognostic significance of various clinical and laboratory findings.

The most recent report comes from Edinburgh, where J. J. R. Duthie and his colleagues ${ }^{1}$ have systematically assessed in 307 adult patients the activity of the disease and their capacity to work. The assessment was carried out at the time of admission to hospital, at discharge, and at approximately 2, 4, 6, and 9 years later, when after the inevitable losses through death and other causes the sample still consisted of 200 patients.

On admission none were fit for all normal activities, 35\% were fit for light work, and $65 \%$ were more severely incapacitated. At discharge the corresponding figures were 11,64 , and $25 \%$. Two years later the figures were even better at 28,44 , and $28 \%$. Thereafter the functional capacity of the group as a whole deteriorated. Nevertheless at the final assessment 9 years after discharge $20 \%$ were fit for all normal activities and a further $41 \%$ were capable of modified employment or all but the heaviest housework.

The functional capacity of individual patients at discharge tended to be maintained thereafter. The situation at this time is therefore a useful guide to future prospects. The ability to achieve a high functional rating did not depend on the disease process becoming inactive, though patients in whom the disease remained active throughout the study fared less well than those who experienced at least one period when the disease was inactive. Almost all the patients presented signs of active disease at some stage and half of them at all four follow-up assessments. There was indeed little support for the view that rheumatoid arthritis is a two-phase disorder in which a period of disease activity is followed by a "burnt-out" stage.

The course of the disease after admission was unrelated to the distribution of affected joints, the physical effort required by a given patient's usual employment, the age at onset, and, in the long run, sex. Clinically what seemed to matter most was the duration of the disease before admission to hospital and the type of course the disease had run up to that time. Patients admitted within a year of the onset achieved a higher functional rating at discharge and at all later assessments than those with a longer duration of disease before admission. This advantage was especially evident among patients in whom the disease had an acute onset and a rapidly progressive course before admission, for $53 \%$ of these were fit for all work at the last assessment as compared with only $20 \%$ of those admitted within a year of onset but in whom the disease had pursued an insidious course.

The patient's functional capacity in general was found to be related to the titre of the sensitized sheep-cell agglutination test. This conclusion was advanced by C. Ragan ${ }^{2}$ and is supported by evidence from other sources previously discussed in this journal. ${ }^{3}$

The adult patient with rheumatoid arthritis and positive serum tests seems more likely to develop not only locomotor incapacity but also the various serious and occasionally fatal complications of the disease. ${ }^{4}$ The death rate at all ages and in both sexes in the Edinburgh study was in fact higher than that in the general population. According to B. M. Ansell and E. G. L. Bywaters ${ }^{5}$ the death rate in juvenile rheumatoid arthritis is also relatively high, but it is evident from their work that the prognosis for patients who develop the disease before the age of 16 is much better than for adults. Factors influencing the outcome seem to be similar in juveniles and adults.

\footnotetext{
'Duthie, J. J. R., Brown, P. E., Truelove, L. H., Baragar, F. D., and Lawrie, A. J., Ann. rheum. Dis., 1964, 23, 193.

2 Ragan, C., Э. Amer. med. Ass., 1949, 141, 124.

3 Brit. med. Ұ., $1962,2,391$. ' Kelligren, J. H., and O'Brien, W. M., Program of 8th Interim Scientific
Session of American Rheumatism Association, December, 1961, p. 27. Ansell, B. M., and Bywaters, E. G. L., Bull. rheum. Dis., 1959, 9, 189.

- Short, C. L., Bauer, W., and Reynolds, W. E., Rheu:matoid Arthritis, Cambridge, Mass., 1957.

' Bywaters, E. G. L., and Dresner, E., Quart. F. Med., 1952, 21, 463.
} 